\title{
Large Outdoor Fires and the Built Environment: Objectives and Goals of Permanent IAFSS Working Group
}

Samuel L. Manzello*, National Institute of Standards and Technology (NIST), Gaithersburg, MD, USA

Sara McAllister, U.S. Forest Service, U.S. Department of Agriculture, Missoula, MT, USA

Sayaka Suzuki, National Research Institute of Fire and Disaster (NRIFD), Chofu, Tokyo, Japan

\section{Demonstrated Need for Permanent Working Group}

Large outdoor fires present a risk to the built environment. Examples often in the international media reports are wildfires that spread into communities, referred to as Wildland-Urban Interface (WUI) fires. WUI fires have destroyed communities throughout the world and are a growing problem in fire safety science. Other examples are large urban fires, including those that have occurred after earthquakes.

Over the past several decades, fire safety science research has spent a great deal of effort to understand fire dynamics within buildings. Research into large outdoor fires, and how to potentially mitigate the loss of structures in such fires, lags behind other areas of fire safety science research [1]. Fire spread in large outdoor fires is incredibly complex, involving the interaction of topography, weather, and fuels. At the same time, common characteristics between fire spread in WUI fires and urban fires have not been fully exploited. Once a wildland fire reaches a community and ignites structures, structure-structure fire spread can occur under similar mechanisms as in urban fire spread.

On June 11, 2017, a workshop, sponsored by the International Association for Fire Safety Science (IAFSS), was held. Seven panelists from around the world presented regional overviews of the large outdoor fire problem related to the built environment in their respective regions. Presentations explored common characteristics between these fires and were arranged as: European View, Asian View, North American View, South American View, and Oceania View.

A significant discussion outcome of the workshop was the desire of the participants to make this topic a permanent working group under the umbrella of the International Association for Fire Safety Science (IAFSS). So far, this has been

\footnotetext{
* Correspondence should be addressed to: Samuel L. Manzello, E-mail: samuel.manzello@nist.gov
} 
done for only one other topic, the Measurement and Computation of Fire Phenomena (MaCFP) working group [2], supporting modeling, a far more wellcharacterized and studied topic in fire safety science.

Due to structure and organization of the workshop, it was apparent that large outdoor fires and the built environment encompass far more than only wildfires, and the working group will address problems with key phenomenological shared characteristics relevant to both urban fires, and wildland-urban interface (WUI) fires. Overall, the workshop was considered a fruitful endeavor and clearly highlighted that much needs to be done in this research area, as it is far behind the well-studied topics that have been around in fire safety science for decades. Many next generation researchers attended and were encouraged to work in this area, as research impact is possible.

A manuscript has been submitted to the official journal of the IAFSS to delineate the key findings of the workshop in fine detail, and form the basis for an international research needs roadmap for this topic. One unique aspect of the paper is that it will also include an African perspective, as this was not presented at the workshop. The interested reader may find all the presentations delivered at the workshop, as well as other details, in an open access report [3].

\section{Objectives and Goals}

Here, the objectives and goals of the permanent working group are delineated. It is proposed that the group consist of three subgroups, prioritized into the following topics: Ignition Resistant Communities (IRC), Emergency Management and Evacuation (EME), and Large Outdoor Firefighting (LOFF). The IRC subgroup will be focused on developing the scientific basis for new standard testing methodologies indicative of large outdoor fire exposures, including the development of necessary testing methodologies to characterize wildland fuel treatments adjacent to communities. The EME subgroup will be focused on developing the scientific basis for effective emergency management strategies for communities exposed to large outdoor fires. The LOFF subgroup will provide a review of various tactics that are used, as well as the various personal protective equipment (PPE), and suggest pathways for research community engagement, including environmental issues in suppressing these fires. The overall objectives are to bring the full depth of knowledge of the IAFSS community to work on these priority topics.

We strongly welcome your participation in this activity and hope you will join us for the kickoff meeting at the Asia-Oceania IAFSS meeting in Taiwan occurring October 21-25, 2018.

Proposed subleader

Topic

Elsa Pastor (Spain)

Enrico Ronchi (Sweden)

Raphaele Blanchi (Australia)
Ignition resistant communities

Emergency management and evacuation

Large outdoor firefighting 


\section{References}

1. Manzello SL (2014) Enabling the investigation of structure vulnerabilities to wind-driven firebrand showers in Wildland Urban Interface (WUI) fires. Fire Saf Sci 11:83-96. https://doi.org/10.3801/IAFSS.FSS.11-83

2. Merci B, Torero JL, Trouvé A (2016) IAFSS working group on measurement and computation of fire phenomena. Fire Technol 52:607. https://oi.org/10.1007/s10694-0160577-3

3. Manzello SL, Blanchi R, Gollner M, McAllister S, Planas E, Rein G, Reszka P, Suzuki S (2017) Summary of workshop large outdoor fires and the built environment. NIST SP 1213 . https://doi.org/10.6028/NIST.SP.1213 